\title{
Resonant optical reflection from AsSb-AIGaAs metamaterials and structures
}

\author{
(C) V.I. Ushanov ${ }^{1}$, V.V. Chaldyshev ${ }^{1}$, V.V. Preobrazhenskiy ${ }^{2}$, M.A. Putyato ${ }^{2}$, B.R. Semyagin ${ }^{2}$ \\ ${ }^{1}$ loffe Institute, \\ 194021 St. Petersburg, Russia \\ ${ }^{2}$ Rzhanov Institute of Semiconductor Physics, Siberian Branch of the Russian Academy of Sciences, \\ 630090 Novosibirsk, Russia \\ E-mail: Decorus2009@mail.ru
}

The optical reflection in periodic structures based on a semiconductor AlGaAs matrix containing twodimensional arrays of plasmonic AsSb nanoinclusions was studied. The number of periods was 12 or 24. The spatial period was near $110 \mathrm{~nm}$ in both cases. In the experimental optical reflection spectra at normal incidence we observed resonant Bragg diffraction with the main peaks at wavelengths of 757 or $775 \mathrm{~nm}$, depending on the spatial period of the nanostructure. The magnitudes of the resonance peaks reached 19 and $31 \%$ for the systems of 12 and $24 \mathrm{AsSb}-\mathrm{AlGaAs}$ layers, while the volume fraction of the nanoinclusions was much less than $1 \%$. In the case of light incident at inclined angles, the Bragg-diffraction pattern shifted according to Wulff Bragg's law. Numerical calculations of the optical reflection spectra were performed using the transfer-matrix method by taking into account the spatial geometry of the structures and the resonance characteristics of the plasmonic AsSb layers.

\section{Acknowledgements}

The research by V.I. Ushanov, V.V. Preobrazhenskiy, M.A. Putyato, B.R. Semyagin was supported by the Russian Foundation for Basic Research, grant No 17-02-01168. V.V. Chaldyshev acknowledges financial support via program of fundamental research by Presidium of the Russian Academy of Sciences. Modern problems of photonics, the probing of inhomogeneous media and materials. 